\title{
Uma experiência de ensino e aprendizagem em matemática: situações- problema no desenvolvimento de competências e habilidades
}

\section{Gabriele Bonotto}

Universidade La Salle e Faculdade Cesuca

gabybonotto@gmail.com

\author{
Vera Lucia Felicetti \\ Universidade La Salle \\ vera.felicetti@unilasalle.edu.br
}

\begin{abstract}
Resumo
Este artigo é recorte de uma dissertação e seu objetivo foi avaliar as contribuições que uma experiência de ensino, baseada na Teoria dos Campos Conceituais, trouxe para o desenvolvimento de competências e habilidades na resolução de situações-problema do campo aditivo. Esta pesquisa corresponde a um estudo de caso com abordagem qualitativa e quantitativa e teve três fases, começando com um pré-teste, que continha situações-problema envolvendo o dia a dia dos educandos e a Teoria dos Campos Conceituais. Após, foi realizada uma experiência de ensino. Durante a experiência, quatro alunos foram acompanhados por meio dos registros de suas falas e produções. Ao fim do percurso planejado, o pós-teste foi aplicado à turma de alunos. Os resultados evidenciaram que trabalhar situações-problema de composição e transformação auxilia no processo de ensino e aprendizagem de conteúdos matemáticos, desenvolvendo novas habilidades, competências, conceitos-em-ação e teoremas-em-ação.
\end{abstract}

Palavras-chave: Situações-problema. Competências e habilidades. Teoria dos Campos Conceituais. Estruturas aditivas.

\section{A teaching and learning experiment in mathematics: problem- situations in the development of competencies and skills}

\begin{abstract}
This article is an overview of a master's thesis and evaluates the contributions that a teaching experiment, based on the Theory of Conceptual Fields, brings to the development of competencies and skills in solving problem-situations in the field of addition. This research is a qualitative and quantitative study, which employs a case study. This study was developed in three stages: first a pre-test was applied, which contained problem-situations according to the daily life of the students and the Theory of Conceptual Fields. After that, a teaching experiment was carried out. During the teaching experiment, four students were monitored by means of oral recordings and productions about what was studied over the course of the experiment. At the end of the planned procedure, the test was reapplied (post-test) to the students in the class. The results showed that working with problem-situations of composition and transformation helps in the teaching and learning process of
\end{abstract}


mathematical content, providing the development of new skills, competencies, concepts-in-action and theorems-in-action.

Keywords: Problem-situations. Competencies and skills. Theory of Conceptual Fields. Addition structures.

\section{Introdução}

Este artigo apresenta como temática o estudo de habilidades e competências, associadas à resolução de situações-problema do Campo Conceitual Aditivo, de acordo com a Teoria dos Campos Conceituais de Gerárd Vergnaud (1993, 1996 e 2014). A Teoria dos Campos Conceituais apresenta o uso de situações-problema como uma possibilidade de aprendizagem de conteúdos matemáticos, no caso deste artigo, as operações de adição e subtração, denominadas pela teoria como campo aditivo. Para realizar tal operação é importante que o indivíduo desenvolva habilidades e competências, como por exemplo, ler e compreender a situação-problema e buscar soluções para a mesma. A justificativa desta associação se dá pela necessidade de melhor entender a relação entre competência, habilidades e a resolução de problemas.

Competência é entendida como sendo a capacidade desenvolvida pelo educando que permite que ele seja eficaz para agir em uma determinada situação, articulando aos recursos cognitivos, suas atitudes, valores e informações (PERRENOUD, 1999). O mesmo autor conceitua habilidade como o uso de uma série de modos operatórios ou de procedimentos mentais utilizados para resolver problemas de uma situação real.

Para Zabala e Arnau (2010), competência é entendida como sendo aquilo que fará com que o indivíduo, ao enfrentar uma situação do seu cotidiano, permitirá resolvê-la de forma satisfatória. Para isso, o sujeito utiliza componentes procedimentais, atitudinais e conceituais, de forma interrelacionada e dialógica. Os autores afirmam que competência está relacionada com a existência e o uso de estruturas cognoscitivas para efetuar uma ação, a qual pode ser entendida como habilidade de resolver situações-problema de forma rápida e eficaz.

Por resolução de problemas compreende-se que é uma determinada situação na qual o indivíduo precisa pensar para encontrar uma possível solução (Dante, 2007), ou articular seus conhecimentos para desenvolver estratégias, trilhando um caminho para desenvolver habilidades e competências. Apesar de nem todas as situações-problema permitirem uma solução, os percursos e as estratégias seguidas ou desenvolvidas pelo aluno contribuem para o processo de aprendizagem do mesmo. No caso dos problemas matemáticos entende-se que para obter uma solução ou 
aproximação da mesma, bem como constatar que determinada situação-problema não tem solução, é preciso utilizar conhecimentos e conceitos da área em foco na situação.

Deste modo, é importante oportunizar aos alunos, durante os primeiros anos na escola, uma grande variedade de tipos de problemas envolvendo adição e subtração de números naturais, uma vez que o desenvolvimento da compreensão de tais operações é fundamental para o conhecimento subsequente em Matemática. Portanto, é necessário que aos alunos seja disponibilizado um conjunto que contemple diferentes situações-problema.

Nesta direção, o objetivo proposto no estudo foi avaliar as contribuições que uma experiência de ensino, baseada na Teoria dos Campos Conceituais de Vergnaud, traz para alunos de uma turma de $3^{\circ}$ ano do Ensino Fundamental no desenvolvimento de competências e habilidades para a resolução de situações-problema do campo aditivo.

\section{Teoria dos Campos Conceituais}

A Teoria dos Campos Conceituais de Vergnaud (1993) foi base para o desenvolvimento deste estudo. De acordo com essa teoria, o conhecimento está organizado em campos conceituais. Um campo conceitual é um conjunto de diferentes situações, problemas, relações, conteúdos, estruturas e operações do pensamento que se entrelaçam durante o processo de aquisição do conhecimento. Por isso, utilizam-se situações-problema para desenvolver conceitos e competências. Para dominar um campo conceitual o indivíduo precisa de um longo período de tempo, a partir da maturidade, da aprendizagem e da experiência.

Segundo Vergnaud (1993), um conceito só adquire sentido pelo educando quando é utilizado para resolver uma situação-problema. Os problemas podem ser teóricos ou práticos e dividem-se em classes que servem para identificar o tipo de situação ali presente. De acordo com a complexidade dessas situações, os alunos podem possuir ou não competências para resolver uma determinada situação.

A teoria entende que a conceitualização é o cerne do desenvolvimento cognitivo. Portanto, a teoria é cognitivista e permite identificar e estudar continuidades e rupturas entre o conhecimento, a partir do campo conceitual, através de um processo de conceitualização de situações reais (VERGNAUD, 1993). De acordo com o autor, trata-se de uma teoria complexa, pois envolve o desenvolvimento das situações, teoremas e conceitos para resolver a situação de forma eficaz. Para Vergnaud (1993; 2014), o professor precisa criar as situações-problema para que os alunos resolvam, pensando na realidade do grupo e nos conteúdos que deseja desenvolver. O aluno necessita aprender novos conceitos e desenvolver teoremas em busca de soluções. 
Segundo Moreira (2002), a Teoria dos Campos Conceituais, criada por Vergnaud, busca investigar as dificuldades conceituais dos educandos, criando estratégias, a fim de superá-las. Moreira (2002) apresenta a teoria de Vergnaud como desenvolvida a partir das teorias de Piaget e Vygotsky. Da epistemologia genética de Piaget, vieram os conceitos de adaptação, esquema, desequílibração e reequilibração. E da teoria sócio-interacionista de Vygotsky, surgiram a interação social, a linguagem, a simbolização no domínio dos campos conceituais, além da zona de desenvolvimento proximal.

Piaget (2007), em sua teoria da epistemologia genética, apresenta os estágios do desenvolvimento, também observados por Vergnaud. Para Vygotsky (1984), o desenvolvimento cognitivo se apresenta a partir da interação social que gera novas possibilidades e conhecimentos. Ele apresenta a zona de desenvolvimento proximal, que se manifesta entre o real, aquilo que o aluno é capaz de fazer sozinho, e o potencial, aquilo que com a ajuda do outro ele é capaz de fazer. Todo esse processo se dá, também, por meio da linguagem (FREITAS, 1994).

Com a seguinte citação, "A organização invariante do comportamento para uma classe de situação dada" (VERGNAUD, 1993, p. 2), o autor explica o que são esquemas. Nestes esquemas é possível pesquisar os conhecimentos-em-ação do educando, ou seja, os elementos cognitivos que permitem a ação do sujeito, tornando-a operatória. $O$ autor também afirma que "a confiabilidade do esquema para o sujeito baseia-se, em última análise, no conhecimento que ele possui, explícito ou implícito, das relações entre o algoritmo e as características do problema a resolver" (VERGNAUD, 1993, p. 3).

Um conceito leva em consideração uma trinca de conjuntos: $\mathrm{C}=(\mathrm{S}, \mathrm{I}, \mathrm{R})$, sendo $\mathbf{S}$ a referência, ou seja, o conjunto de situações que dão sentido ao conceito; o I é o significado, as diferentes invariantes na qual a operacionalidade dos esquemas é baseada; e $\mathbf{R}$ é o significante, o conjunto das formas expressas através da linguagem, ou não, mas que apresenta de forma simbólica o conceito, assim como suas propriedades e os procedimentos de tratamento das situações (VERGNAUD, 1993). Para o autor, esquema é a forma como o educando organiza as invariantes, ou seja, os componentes cognitivos, para lidar com um tipo de situação-problema. As características dos esquemas são: ser relacionado a uma situação específica e organizar as invariantes atuando de forma implícita na dada situação.

Neste mesmo sentido, o autor apresenta o conceito de teorema-em-ação como sendo relações matemáticas que os indivíduos levam em consideração, ao escolher a operação ou operações para solucionar problemas. Estes não são específicos e surgem de forma intuitiva no fazer do aluno e são verdadeiros apenas em um conjunto de situações. Portanto, teoremas-em-ação, 
tratam de caminhos que o professor pode utilizar para trabalhar os conceitos com determinado aluno.

Para Vergnaud (1993), no Campo Conceitual das Estruturas Aditivas, as situações requerem o uso da adição, da subtração ou da combinação das duas. Assim, esse campo conceitual aborda um conjunto de situações, que no tratamento são utilizadas adições e subtrações, e é também a junção dos teoremas e conceitos que possibilitam trabalhar com essas situações como tarefas matemáticas. Portanto, os conceitos de medida, transformação temporal por diminuição ou aumento, de composição binária de medidas, de relação de comparação quantificada, de inserção de número natural, de composição, de número natural, de transformação, de número relativo, entre outros, são componentes das estruturas aditivas e são acompanhadas por teoremas verdadeiros. Como os alunos que estão envolvidos encontram-se no estágio das operações concretas, eles estão aptos a realizar os teoremas em ação, já que os educandos são capazes de classificar, numerar, seriar, calcular, interpretar, entre outras habilidades necessárias para resolver situações-problema referente às estruturas aditivas.

Dentro das estruturas aditivas existem categorias de relações (VERGNAUD, 2014). Estas serão apresentadas juntamente com os exemplos a seguir.

Situação-problema 1: Lucas foi na fruteira e comprou dois tipos de frutas. Ele comprou 12 maçãs e 5 laranjas. Quantas frutas ele comprou?

Situação-problema 2: Joana tinha 12 figurinhas. 5 eram de estrelas e as outras eram de corações. Quantas figurinhas eram de corações?

A primeira situação envolve a composição dos dois tipos de frutas, que são as partes, mas que geram um total de apenas um elemento, frutas, resultando no todo. Segundo Santana (2010), a partir desse tipo de situação-problema podem ser trabalhados vários conceitos, a saber: adição, juntar, medida de um conjunto e compor.

A segunda situação exibe composição do número de figurinhas. Existe uma parte o todo, tornando-se necessário conhecer a outra parte.

Portanto, a composição, relatada na situação-problema 1, é uma categoria que envolve situações-problema que apresentam duas partes e o todo. Para trabalhar a composição pode-se trabalhar perguntando o todo e dando o valor das partes ou informando o valor do todo e uma parte e questionando o valor da outra parte (SANTANA, 2010). 
Situação-problema 3: Maria tem uma coleção de bichos de pelúcia. Ela tinha 14 na segunda-feira, mas na terça-feira ela ganhou alguns bichos de pelúcia de seus amigos. Quando foi contar ela descobriu que ficou com 19 bichos. Quantos bichos de pelúcia Maria ganhou?

A situação-problema 3 demonstra a categoria da transformação. Esta possui uma situação inicial, uma transformação que conduz a uma situação final (SANTANA, 2010).

Nesta situação ocorre uma transformação positiva do estado inicial. Nela são informados os valores do estado inicial e do estado final e temos que descobrir a transformação. A transformação também pode ser negativa.

Situação-problema 4: Juliana fez cupcakes para a sobremesa. Seu irmão comeu 3 antes do jantar e sobraram 11. Quantos cupcakes Juliana fez?

Neste problema ocorre um problema de inversão, também de transformação. Nele são informados os valores do estado final e da transformação e é necessário descobrir o estado inicial.

Ainda há a categoria da comparação, na qual é possível relacionar duas quantidades por meio da comparação. A comparação pode ser de medida, de relação e de duas medidas (VERGNAUD, 1996 apud SANTANA, 2010). Por exemplo, Joana tem dinheiro para comprar sorvete e Marina tem $\mathrm{R} \$ 7,00$ a menos que Joana. Sabendo que Marina tem $\mathrm{R} \$ 18,00$, quantos reais tem Joana? Esta situação apresenta um referido 7, um referente 18 e uma relação entre eles.

Esta categoria, entretanto, não será abordada neste artigo devido aos conteúdos que são trabalhados no primeiro trimestre do terceiro ano do Ensino Fundamental e pelas habilidades e competências a serem desenvolvidas até esse nível de ensino. Dentro destas três categorias Magina, Campos, Nunes e Citirana (2001) criaram uma subdivisão, demonstrando os níveis de complexidade existente nas situações-problema. Tais subdivisões podem ser vistas no quadro 1 no qual são apresentadas as subdivisões da composição, transformação e comparação as seguintes subcategorias: protótipo, $1^{\mathrm{a}}$ extensão e $4^{\mathrm{a}}$ extensão. As subdivisões referentes à comparação não foram incluídas no Quadro 1, pois não foram abordadas na experiência de ensino como pode ser visto na adaptação feita para representar apenas as situações-problema da experiência de ensino. 


\section{Quadro 1 - Tipos de situação-problema}

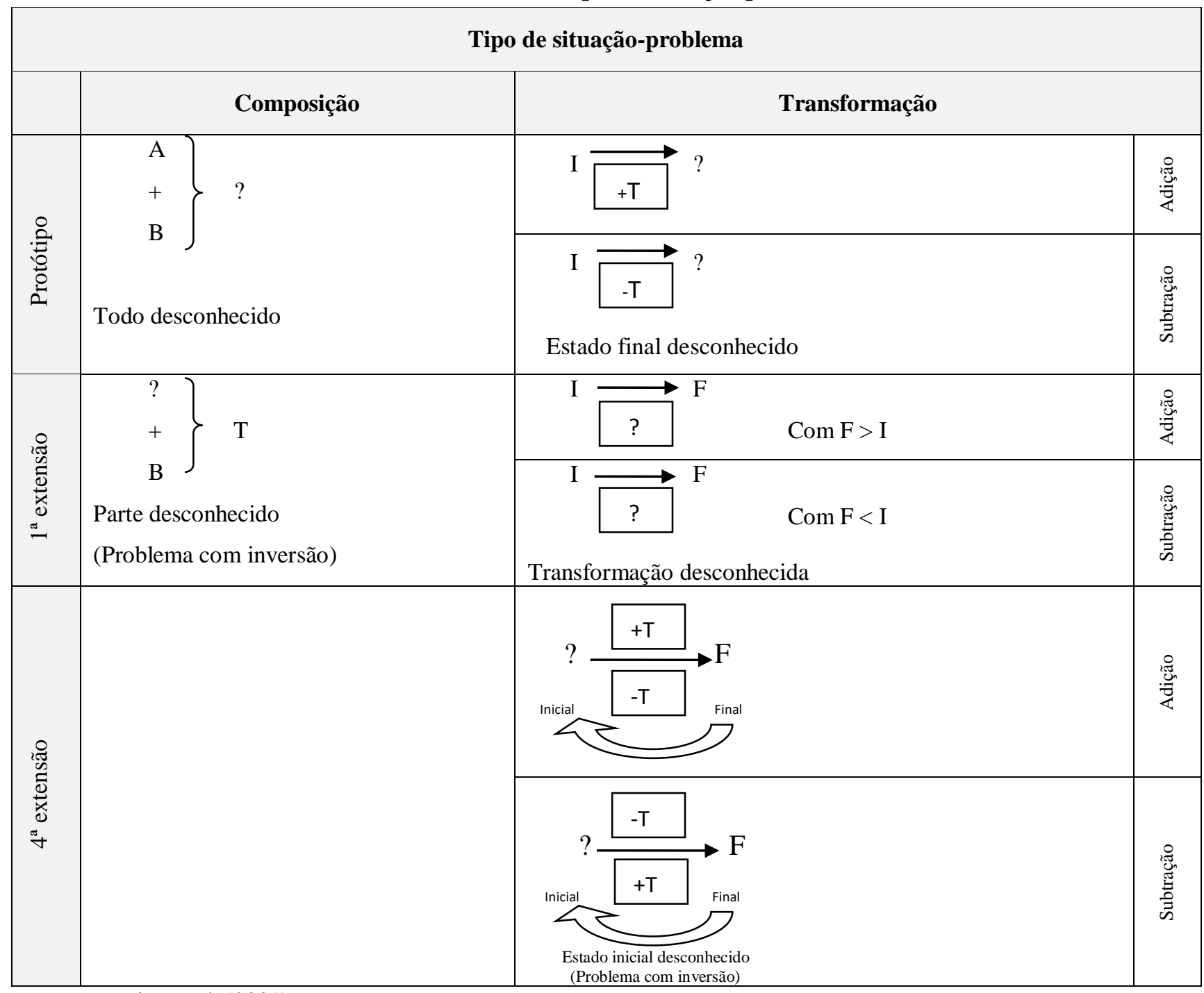

Fonte: Magina et al. (2001).

Os problemas protótipo são aqueles que apresentam menor complexidade. Estes podem ser de composição e transformação. Nos problemas de composição as duas partes são conhecidas, desejando-se saber o todo, como visto na situação-problema 1, citada anteriormente. As situações prototípicas permitem que as crianças utilizem esquemas já desenvolvidos no seu cotidiano antes mesmo de entrar na escola.

As situações-problemas de $1^{\mathrm{a}}$ extensão apresentam maior dificuldade do que as situações prototípicas e podem ser de composição e de transformação. Na composição sabe-se uma parte e o todo, querendo-se chegar a outra parte, como é citado na situação-problema 2. Na transformação tem-se as quantidades iniciais e finais e precisa-se descobrir a transformação, como já foi exemplificado na situação-problema 3. 
As situações-problema de $4^{\mathrm{a}}$ extensão, que apresentam inversão, podem ser de transformação e comparação e apresentam maior complexidade que os problemas anteriores. No de transformação não se conhece o estado inicial. São exemplos de transformação de $4^{\mathrm{a}}$ extensão a situação-problema 4.

As situações-problema de composição e transformação que envolvem protótipo, $1^{\mathrm{a}}$ e $4^{\mathrm{a}}$ extensão foram utilizadas no pré-teste, no pós-teste e durante a experiência de ensino realizados durante a pesquisa aqui apresentada.

Segundo Antunes (2001), existe uma série de habilidades que precisa ser trabalhada desde a Educação Infantil até o Ensino Médio, e, a partir do momento em que se adquire uma habilidade, necessita-se desta para conquistar outras habilidades e concretizar competências. $\mathrm{O}$ autor ainda apresenta as habilidades de consultar, conferir, observar, conhecer, separar, comparar, reunir, compreender, como construídas durante a Educação Infantil e o processo de alfabetização.

Para Alsina Pastells (2009), as habilidades a serem desenvolvidas no terceiro ano do Ensino Fundamental são similares às citadas anteriormente: analisar, aplicar, classificar, compor, demonstrar, descrever, explicar, identificar, interpretar, numerar, relacionar, somar, subtrair, transformar e multiplicar. Estas precisam ser trabalhadas com o objetivo de alcançar as competências de desenvolver o raciocínio lógico-matemático; compreender escritas numéricas; comparar, ordenar e identificar números naturais, compreendendo o valor de cada algarismo; reconhecer os números e as operações matemáticas; compreender as operações matemáticas em três níveis: técnico (o número), compreensivo (significado da operação) e aplicado (aplicação no cotidiano), reconhecer os números e as operações matemáticas; compreender as operações matemáticas em três níveis: técnico (o número), compreensivo (significado da operação) e aplicado (aplicação no cotidiano) e escolher e aplicar as técnicas de resolução de problemas mais adequadas para resolução do problema.

Essas habilidades e competências são descritas também por Vergaud (1993), ao discorrer sobre as invariantes operatórias e os esquemas a serem utilizados para a resolução de situaçõesproblema.

\section{Metodologia}

O estudo aqui apresentado correspondeu a um estudo de caso, de caráter quantitativo e qualitativo, tratando-se de uma experiência de ensino, realizada em uma turma na qual uma das autoras era docente, em uma escola privada do município de Porto Alegre/RS. A turma era composta por 17 alunos, sendo que 16 alunos participaram da pesquisa, pois uma aluna possuía necessidades 
educativas especiais e tinha currículo adaptado. A turma possuía 9 meninas e 8 meninos entre 7 e 8 anos de idade. A seguir apresentam-se as fases da experiência de ensino.

Na primeira frase, de diagnóstico, houve a aplicação de um pré-teste (APÊNDICE A) para os alunos de uma turma de terceiro ano do Ensino Fundamental, de uma escola particular. Neste pré-teste apresentavam-se dez problemas matemáticos que envolviam situações-problemas divididas entre: composição protótipo, composição $1^{\mathrm{a}}$ extensão, transformação protótipo, transformação $1^{\mathrm{a}}$ extensão e transformação $4^{\mathrm{a}}$ extensão. A partir dos dados obtidos no pré-teste, foram escolhidos quatro estudantes para fins de acompanhamento durante a experiência de ensino: dois que apresentaram maior número de acertos e dois que obtiveram menor número de acertos. Tais alunos foram acompanhados por meio dos registros de suas falas e de produções sobre o que foi trabalhado ao longo da experiência. Eles formam denominados: Ônix, Topázio, Rubi e Esmeralda.

A segunda fase do estudo tratou do planejamento e da execução da experiência de ensino. O planejamento pautou-se em situações-problema que propiciassem aos educandos as diferentes complexidades do campo aditivo, pensando em propostas relacionadas com a realidade dos mesmos. A experiência de ensino foi desenvolvida a partir da Teoria dos Campos Conceituais e também do desenvolvimento de habilidades e competências, sendo a competência principal a ser desenvolvida a de resolução de situações-problema. Da Teoria dos Campos Conceituais utilizaramse as situações-problema como instrumento para que os alunos desenvolvessem habilidades e competências, pois Vergnaud (1993) e Perrenoud (1999) afirmam que a partir do uso de situaçõesproblema, voltadas para o cotidiano do aluno, existe a possibilidade de desenvolvimento de novos conhecimentos.

Após a efetivação das aulas correspondentes à experiência de ensino foi realizado o pósdiagnóstico, isto é, aplicou-se o pós-teste que correspondeu ao mesmo instrumento aplicado no início do semestre, quando os alunos, em março, estavam recém-vindos do segundo ano. Observase que, embora a professora tenha realizado registros diários de quatro alunos, os demais também tiveram atenção e cuidado da docente durante todo o processo de ensino e aprendizagem.

Na aplicação do pré-teste estavam presentes 16 dos 17 alunos da turma em questão. Após análise do pós-teste, os dados forma colocados em tabelas juntamente com os dados do pré-teste. Foram mantidos os tipos de estratégias para fazer uma comparação entre o que os alunos fizeram antes e após a experiência de ensino.

A seguir apresenta-se a análise dos dados obtidos durante a aplicação do pré-teste, experiência de ensino e pós-teste, focando no desempenho dos 4 alunos escolhidos. 


\section{Experiência de ensino em matemática}

As atitudes e aprendizagens dos alunos Ônix, Topázio, Rubi e Esmeralda foram observadas e anotadas durante toda a experiência de ensino. A seguir segue uma comparação entre as estratégias utilizadas por eles no pré-teste e no pós-teste, representadas na Quadro 2.

Quadro 2 - Comparação do pré-teste e o pós-teste dos 4 alunos

\begin{tabular}{|c|c|c|c|c|c|c|c|c|}
\hline \multirow{2}{*}{$\begin{array}{l}\text { Situação- } \\
\text { problema }\end{array}$} & \multicolumn{2}{|c|}{ Ônix } & \multicolumn{2}{|c|}{ Topázio } & \multicolumn{2}{|c|}{ Rubi } & \multicolumn{2}{|c|}{ Esmeralda } \\
\hline & Pré-teste & Pós-teste & Pré-teste & Pós-teste & Pré-teste & Pós-teste & Pré-teste & Pós-teste \\
\hline A & $\begin{array}{c}\text { Erro na } \\
\text { montagem }\end{array}$ & $\begin{array}{c}\text { Usou } \\
\text { algarismos }\end{array}$ & $\begin{array}{c}\text { Usou } \\
\text { algarismos }\end{array}$ & $\begin{array}{c}\text { Usou } \\
\text { algarismos }\end{array}$ & $\begin{array}{c}\text { Usou } \\
\text { algarismos }\end{array}$ & $\begin{array}{c}\text { Usou } \\
\text { algarismos }\end{array}$ & $\begin{array}{c}\text { Errou a } \\
\text { montagem do } \\
\text { cálculo }\end{array}$ & $\begin{array}{c}\text { Usou } \\
\text { algarismos }\end{array}$ \\
\hline $\mathrm{E}$ & $\begin{array}{c}\text { Erro na } \\
\text { montagem }\end{array}$ & $\begin{array}{c}\text { Usou } \\
\text { algarismos }\end{array}$ & $\begin{array}{l}\text { Deixou em } \\
\text { branco }\end{array}$ & $\begin{array}{c}\text { Usou } \\
\text { algarismos }\end{array}$ & $\begin{array}{c}\text { Usou } \\
\text { desenhos }\end{array}$ & $\begin{array}{c}\text { Usou } \\
\text { algarismos e } \\
\text { desenhos }\end{array}$ & $\begin{array}{l}\text { Usou os } \\
\text { dedos }\end{array}$ & $\begin{array}{c}\text { Usou } \\
\text { algarismos }\end{array}$ \\
\hline B & Em branco & $\begin{array}{c}\text { Usou } \\
\text { algarismos }\end{array}$ & $\begin{array}{c}\text { Usou } \\
\text { algarismos }\end{array}$ & $\begin{array}{c}\text { Usou } \\
\text { algarismos }\end{array}$ & $\begin{array}{c}\text { Usou } \\
\text { algarismos }\end{array}$ & $\begin{array}{c}\text { Usou } \\
\text { algarismos }\end{array}$ & $\begin{array}{l}\text { Usou os } \\
\text { dedos }\end{array}$ & $\begin{array}{c}\text { Usou } \\
\text { algarismos }\end{array}$ \\
\hline $\mathrm{C}$ & $\begin{array}{l}\text { Operação } \\
\text { contrária }\end{array}$ & $\begin{array}{c}\text { Erro na } \\
\text { montagem }\end{array}$ & $\begin{array}{c}\text { Usou } \\
\text { operação } \\
\text { contrária }\end{array}$ & $\begin{array}{c}\text { Usou } \\
\text { algarismos }\end{array}$ & $\begin{array}{c}\text { Errou a } \\
\text { montagem do } \\
\text { cálculo }\end{array}$ & $\begin{array}{c}\text { Usou } \\
\text { algarismos }\end{array}$ & $\begin{array}{c}\text { Erro de } \\
\text { interpretação }\end{array}$ & $\begin{array}{c}\text { Usou } \\
\text { algarismos }\end{array}$ \\
\hline $\mathrm{H}$ & Em branco & $\begin{array}{c}\text { Usou } \\
\text { algarismos }\end{array}$ & $\begin{array}{l}\text { Deixou em } \\
\text { branco }\end{array}$ & $\begin{array}{c}\text { Usou } \\
\text { algarismos }\end{array}$ & $\begin{array}{c}\text { Usou } \\
\text { desenhos }\end{array}$ & $\begin{array}{c}\text { Usou } \\
\text { algarismos }\end{array}$ & $\begin{array}{c}\text { Usou os } \\
\text { dedos }\end{array}$ & $\begin{array}{c}\text { Usou } \\
\text { algarismos }\end{array}$ \\
\hline I & Em branco & $\begin{array}{l}\text { Operação } \\
\text { contrária }\end{array}$ & $\begin{array}{l}\text { Deixou em } \\
\text { branco }\end{array}$ & $\begin{array}{c}\text { Usou } \\
\text { algarismos }\end{array}$ & $\begin{array}{c}\text { Usou } \\
\text { desenhos }\end{array}$ & $\begin{array}{c}\text { Usou } \\
\text { algarismos }\end{array}$ & $\begin{array}{l}\text { Usou os } \\
\text { dedos }\end{array}$ & $\begin{array}{c}\text { Usou } \\
\text { algarismos }\end{array}$ \\
\hline $\mathrm{D}$ & $\begin{array}{c}\text { Errou na } \\
\text { interpretação }\end{array}$ & $\begin{array}{c}\text { Usou } \\
\text { algarismos }\end{array}$ & $\begin{array}{c}\text { Erro de } \\
\text { interpretação }\end{array}$ & $\begin{array}{c}\text { Usou } \\
\text { algarismos }\end{array}$ & $\begin{array}{c}\text { Erro de } \\
\text { interpretação }\end{array}$ & $\begin{array}{c}\text { Usou } \\
\text { algarismos }\end{array}$ & $\begin{array}{l}\text { Usou cálculo } \\
\text { mental }\end{array}$ & $\begin{array}{c}\text { Usou } \\
\text { algarismos }\end{array}$ \\
\hline $\mathrm{F}$ & $\begin{array}{c}\text { Erro na } \\
\text { montagem }\end{array}$ & $\begin{array}{c}\text { Usou } \\
\text { algarismos }\end{array}$ & $\begin{array}{l}\text { Deixou em } \\
\text { branco }\end{array}$ & $\begin{array}{c}\text { Errou a } \\
\text { montagem do } \\
\text { cálculo }\end{array}$ & $\begin{array}{c}\text { Usou } \\
\text { desenhos }\end{array}$ & $\begin{array}{c}\text { Usou } \\
\text { algarismos }\end{array}$ & $\begin{array}{l}\text { Usou os } \\
\text { dedos }\end{array}$ & $\begin{array}{c}\text { Usou } \\
\text { algarismos }\end{array}$ \\
\hline G & $\begin{array}{l}\text { Operação } \\
\text { contrária }\end{array}$ & $\begin{array}{c}\text { Usou } \\
\text { algarismos }\end{array}$ & $\begin{array}{l}\text { Deixou em } \\
\text { branco }\end{array}$ & $\begin{array}{c}\text { Usou } \\
\text { operação } \\
\text { contrária }\end{array}$ & $\begin{array}{c}\text { Usou } \\
\text { algarismos }\end{array}$ & $\begin{array}{c}\text { Usou } \\
\text { algarismos }\end{array}$ & $\begin{array}{c}\text { Usou } \\
\text { operação } \\
\text { contrária }\end{array}$ & $\begin{array}{c}\text { Usou } \\
\text { operação } \\
\text { contrária }\end{array}$ \\
\hline $\mathrm{J}$ & Em branco & $\begin{array}{c}\text { Usou } \\
\text { algarismos }\end{array}$ & $\begin{array}{l}\text { Deixou em } \\
\text { branco }\end{array}$ & $\begin{array}{l}\text { Cálculo } \\
\text { mental }\end{array}$ & $\begin{array}{c}\text { Usou } \\
\text { desenhos }\end{array}$ & $\begin{array}{c}\text { Usou } \\
\text { desenhos }\end{array}$ & $\begin{array}{l}\text { Usou os } \\
\text { dedos }\end{array}$ & $\begin{array}{c}\text { Usou } \\
\text { algarismos }\end{array}$ \\
\hline
\end{tabular}

Fonte: elaborado pela autora.

O aluno Ônix demonstrou evolução em sua aprendizagem. No pré-teste não havia acertado qualquer situação-problema; já no pós-teste obteve oito acertos, errando apenas a resolução das situações-problema C e I, conforme demonstra o Quadro 2.

O aluno Ônix demonstrava ter um pensamento concreto no início da experiência de ensino. Durante as aulas iniciais ele demonstrou muita dispersão e não conseguia resolver as situaçõesproblema. Em vários momentos não sabia qual operação deveria utilizar e utilizava números aleatórios para a resolução. Apresentava também uma leitura segmentada e sem compreensão. No início da experiência de ensino a utilização do ábaco era motivo de brincadeira, mas no decorrer das aulas tornou-se um auxilio na resolução. A Figura 1 apresenta uma das resoluções feitas pelo aluno Ônix e demonstra a sua evolução durante a experiência de ensino. 


\section{Figura 1 - Resolução do aluno Ônix}

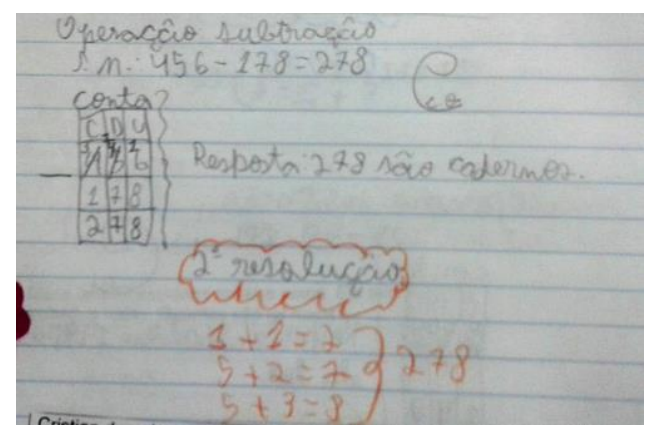

Fonte: Documentos arquivados/analisados da pesquisadora.

O resultado da experiência de ensino é revelado através do número de acertos no pós-teste do aluno Ônix. Durante a experiência de ensino, ficou evidente que o uso do ábaco de copos e da leitura auxiliou o aluno a resolver situações-problema em sala de aula. A seguir apresenta-se a análise referente ao aluno Topázio.

O aluno Topázio também demonstrou evolução em sua aprendizagem. No pré-teste ele acertou apenas duas situações-problema, porém no pós-teste alcançou oito acertos, errando, assim como o aluno Ônix, apenas a resolução de duas situações-problema, F e G, conforme demonstra o quadro 2. Observa-se que o número de acertos do aluno Topázio e do aluno Ônix no pós-teste equivale ao número de acertos do aluno Rubi no pré-teste, sendo que o aluno Rubi era o aluno com o maior número de acertos.

O fato de o aluno Topázio ter deixado várias questões em branco no pré-teste e no pósteste conseguir resolver a maioria delas de forma correta pode ser um indicativo de que durante a experiência de ensino o aluno conseguiu adquirir novas habilidades e competências, assim como desenvolver os seus teoremas-em-ação. A figura 2 demonstra a evolução do aluno Topázio na resolução das situações-problema.

Figura 2 - Resolução do aluno Topázio

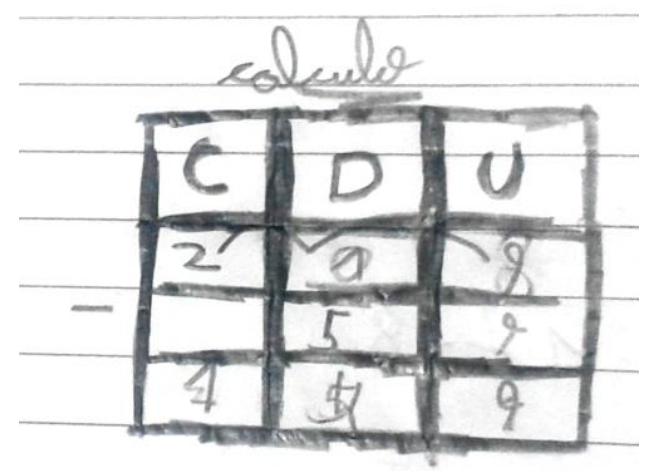

Fonte: Documentos arquivados/analisados da pesquisadora. 
O aluno Rubi também demonstrou evolução em sua aprendizagem. No pré-teste ele havia acertado oito situações-problema, mas no pós-teste atingiu dez acertos, ou seja, o aluno acertou todas as situações-problema do pós-teste.

O aluno Rubi demonstrou evolução na sua aprendizagem. Não apenas pelo aumento no número de acertos, mas também porque ele conseguiu alterar suas estratégias. Passou a utilizar mais cálculos com algarismos e menos desenhos em suas resoluções, o que demonstra um pensamento mais abstrato e menos concreto. A figura 3 demonstra a resolução do aluno Rubi no início da experiência de ensino.

Figura 3 - Resolução do aluno Rubi

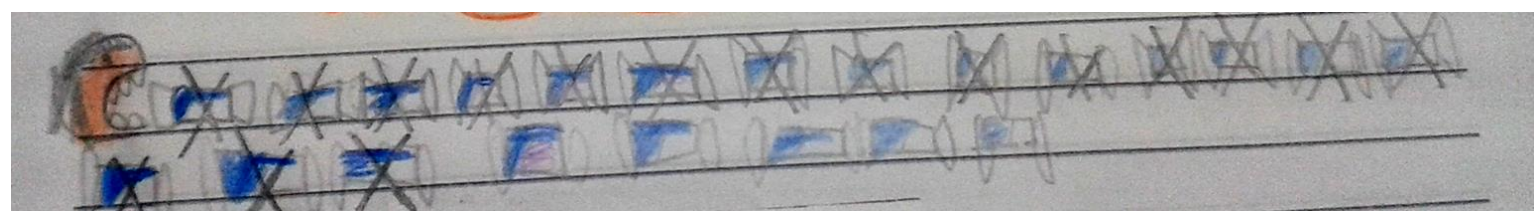

Fonte: Documentos arquivados/analisados da pesquisadora.

A aluna Esmeralda também demonstrou evolução em sua aprendizagem. No pré-teste seu número de acertos foi sete e no pós-teste atingiu nove acertos, errando apenas a situação-problema G, conforme o quadro 2. O mesmo quadro demonstra que a aluna conseguiu alterar as estratégias de resolução para resolver as situações-problema de forma correta.

Figura 4 - Resolução da aluna Esmeralda

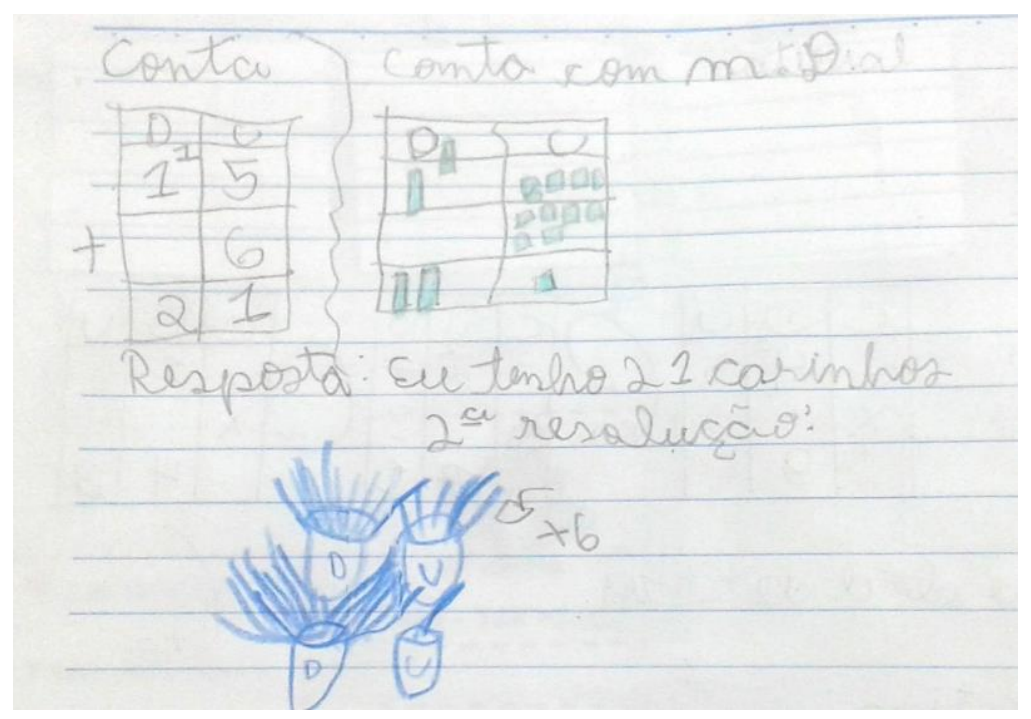

Fonte: Documentos arquivados/analisados da pesquisadora.

Portanto, todos os alunos observados pela professora durante a experiência de ensino conseguiram aumentar sua capacidade de resolver situações-problema. Os alunos Ônix e Topázio conseguiram atingir os conhecimentos prévios para resolver as situações-problema, como ler, 
interpretar e calcular. E ainda conseguiram aumentar consideravelmente o número de acertos no pós-teste.

Já os alunos Rubi e Esmeralda conseguiram pensar de forma mais abstrata, pois, além de resolver as situações-problema com competência, ainda conseguiram priorizar o uso de algarismos na resolução de situações-problema, diminuindo o uso de materiais concretos e desenhos para resolução.

\section{Discussão}

A Teoria dos Campos Conceituais foi aplicada durante a experiência de ensino não apenas no planejamento das situações-problema, mas também na execução das atividades e nas suas intencionalidades.

Quando os alunos Ônix e Topázio não conseguiam resolver uma situação-problema e algum colega pedia para ajudá-los havia um momento de interação. $\mathrm{O}$ aluno que estava ajudando precisava criar outras situações-problema baseadas na realidade deles para explicar e interpretar o enunciado sem evidenciar a resposta da atividade. Com o tempo os alunos Ônix e Topázio saíram do que era apenas potencial e passaram para o real, resolvendo efetivamente as situações-problema trabalhadas. Ficou evidente no relato da experiência de ensino que eles apresentaram evolução em sua aprendizagem e conseguiram resolver com maior facilidade as situações-problemas propostas.

Todo esse processo se deu, também, por meio da linguagem, ou seja, dos momentos de diálogo e interlocução ocorridos na experiência de ensino entre a professora e os alunos e também dos alunos com seus pares. Vygotsky (1984) revela que a linguagem é responsável pela regulação da atividade psíquica humana, é por ela que passam as estruturas dos processos cognitivos. Também é através dela que o indivíduo se constitui como sujeito e possibilita interações que possibilitam a construção do conhecimento. Durante a experiência de ensino os alunos foram estimulados a utilizar a linguagem para expressar suas aprendizagens, buscando explicar e registrar a forma como constituíram o pensamento, como escolheram a operação e como realizaram o cálculo.

Vergnaud (1993) apresenta a linguagem como fator importante no processo da conceitualização. Durante a experiência de ensino os alunos foram estimulados a falar sobre como chegaram ao resultado final. $\mathrm{O}$ autor afirma, contudo, que é muito difícil para as crianças explicitar as regras de como identificaram a operação e de como fizeram o cálculo, mesmo que eles consigam efetuar as operações matemáticas. $\mathrm{O}$ fato de eles conseguirem resolver e não conseguirem expressar as regras, portanto, demonstra um conhecimento implícito. Esse conhecimento implícito está inserido nos esquemas. Os alunos, no entanto, estavam durante toda a experiência de ensino 
demonstrando os esquemas que estavam desenvolvendo. Para o autor, um esquema sempre se apoia em um conceito implícito.

$\mathrm{Na}$ Teoria dos Campos Conceituais a linguagem exerce uma função tríplice. Ela ajuda a identificar as invariantes, a raciocinar e fazer inferências e a antecipar metas, efeitos e controles de ação.

Para resolver as situações-problema os alunos utilizaram a numeração de posição, a enumeração e a conceitualização, que estão relacionadas. Eles precisaram conciliar as informações fornecidas pela situação-problema com os termos de unidade, dezena e centena. Os erros que apresentaram referentes à montagem do cálculo estão relacionados com a numeração de posição, a enumeração e a conceitualização. Como durante o tempo da experiência de ensino foram trabalhadas situações-problema e também cálculos, eles conseguiram diminuir esse tipo de erro.

O funcionamento cognitivo do aluno diante de uma situação-problema está baseado nos esquemas que ele já possui e que pode vir a desenvolver. Os esquemas na aprendizagem da Matemática podem envolver deslocamento, generalização, transferência ou descontextualização. Para que as crianças aprendam os diferentes esquemas é preciso que sejam colocadas diante de diferentes situações-problema, para que possam verificar as semelhanças e as diferenças entre elas e encontrem os critérios para chegar ao esquema a ser utilizado de forma operatória. Por isso, os alunos foram desafiados com situações-problema de composição e transformação em momentos diversos da experiência de ensino.

À medida que os alunos vão avançando no processo cognitivo, precisam utilizar vários esquemas como: enumeração, reagrupamento, adições, enumerações parciais, adições e subtrações. Verifica-se que durante a experiência de ensino os alunos precisaram utilizar tais esquemas, enumerando os itens da situação-problema, realizando adições e subtrações após identificar a operação correta, entre outros (VERGNAUD, 1993).

Ainda segundo o autor, reconhecer as invariantes é fundamental para a generalização do esquema. As invariantes podem ser conhecimentos-em-ação ou conceitos-em-ação, e podem ser de três tipos. As invariantes do tipo "proposição" podem ser falsas ou verdadeiras. Teoremas-em-ação é um exemplo de invariante deste tipo. Por exemplo, quando uma criança descobre que não é preciso começar a contar o número para achar o total e sim começar a contar de uma parte que ele já conhece, ele está utilizando um teorema-em-ação. Este teorema-em-ação foi descoberto pelo aluno Ônix durante a experiência de ensino. No início da experiência se ele precisava somar 12 e 7 , pegava os palitos e começava a contar, 1, 2, 3, ... até chegar no 12 e depois acrescentava os 7 palitos. No final da experiência de ensino ele já conseguia acionar o teorema-em-ação e começar a contar a partir do 12 . 
Com isso, Ônix conseguiu desenvolver algumas habilidades e competências que ainda não possuía antes da experiência de ensino. As principais habilidades identificadas pela professora foram ler, interpretar e compreender, habilidades essas necessárias para a resolução de situaçõesproblema. Também foram identificadas as habilidades de classificar, separar, reunir, seriar, interagir e transferir.

O conjunto destas habilidades permitiu ao aluno tornar-se competente em identificar corretamente os dados e as operações, resolver as situações-problema envolvendo subtração e adição, compreender e analisar mensagens orais e escritas que expressem situações a serem resolvidas, da vida real ou imaginária, relacionar problemas com os conhecimentos matemáticos aprendidos, escolher e aplicar as técnicas de resolução de problemas mais adequadas, desenvolver o raciocínio lógico-matemático e compreender as operações matemáticas em três níveis: técnico (o número), compreensivo (significado da operação) e aplicado (aplicação no cotidiano) como postulado por Alsina Pastells (2009). As habilidades e competências desenvolvidas por Ônix durante a experiência de ensino foram confirmadas por meio do pós-teste, uma vez que o aluno passou de zero no pré-teste para oito acertos no pós-teste.

As invariantes do tipo "função proposicional” são indispensáveis às estruturas aditivas, trabalhadas durante a experiência de ensino. Esse tipo de invariante envolve os conceitos de estado inicial, cardinal, coleção, transformação e relação quantificada. Estes são conceitos-em-ação. Essas invariantes, portanto, foram trabalhadas na experiência de ensino nas situações-problema de composição e transformação.

Os conceitos de estado inicial são trabalhados nas situações-problema de $4^{\mathrm{a}}$ extensão, quando o aluno desconhece o estado inicial de alguma situação. Este tipo de situação-problema foi considerado mais difícil por toda a turma e pelos alunos em foco na experiência de ensino. $\mathrm{O}$ conceito de coleção é trabalhado desde a Educação Infantil, mas reflete nas aprendizagens de todos os anos do Ensino Fundamental. Um exemplo foi quando o aluno Rubi questionou sobre a centena - de como uma centena poderia ser cem unidades.

Esses conceitos, porém, são dificilmente explicitados pelas crianças. Elas conseguem utilizá-los, mas não explicitá-los. Por isso, durante a experiência de ensino, os alunos não conseguiam explicar como haviam chegado até a operação, ou como a haviam resolvido.

Para desenvolver esses conceitos e tornar os alunos competentes em resolução de situações-problema, portanto, foram utilizadas situações-problema desafiadoras, invariantes (teoremas-em-ação e conceitos-em-ação) e a linguagem. Os conceitos-em-ação e os teoremas-emação (invariantes) foram desenvolvidos por intermédio dos desafios contidos nas resoluções das situações-problema e que levaram às habilidades juntar, separar, transferir, consultar, conferir, ler, 
compreender, entre outras. A linguagem foi trabalhada na experiência de ensino quando os alunos eram questionados e precisavam elaborar respostas sobre como resolver as situações ou porque identificaram aquela operação. Ainda a linguagem apareceu quando os alunos se dispuseram a auxiliar os colegas na resolução das atividades. Eles necessitavam criar perguntas ou falas para ajudar os colegas, mas sem lhes dar a resposta.

Esse conjunto promoveu o sucesso da experiência de ensino. A Teoria dos Campos Conceituais, portanto, exerce influência na prática de ensino e pode ser utilizada pelo professor para facilitar o desenvolvimento de conceitos e competências a partir de situações-problema.

\section{Considerações Finais}

Durante a experiência de ensino foram trabalhadas situações-problema de composição e transformação. Para isso, os alunos precisaram utilizar diferentes habilidades: ler e compreender o enunciado, observando as suas partes e consultando os dados mais apropriados para resolver a situação-problema; conhecer e comparar os diferentes tipos de situação-problema trabalhados e enumerar os algarismos; transferir os conhecimentos utilizados para novas situações e combinar as estratégias a fim de formar novos esquemas; relatar para a professora as estratégias descobertas e interagir com os colegas para aprender e ensinar; aplicar seus conhecimentos por meio do cálculo, da soma e da subtração. A definição de Vergnaud (1993) corrobora a construção de novos conceitos, quando é preciso situações desafiadoras, invariantes e linguagem.

Portanto, são muitas as contribuições de ensino que a Teoria dos Campos Conceituais agrega ao ensino da matemática no Ensino Fundamental. O pré-teste, o desenvolvimento da experiência de ensino e o pós-teste evidenciaram que trabalhar com situações-problema do campo aditivo auxiliam os educandos a adquirir habilidades e competências necessárias à faixa etária estudada.

A partir da experiência de ensino percebeu-se que, para desenvolver a competência de resolução de situações-problema, é necessário utilizar habilidades, tais como: interagir, demonstrar, relatar, combinar, analisar, seriar, transferir, conferir, consultar, classificar, observar, interpretar, comparar, separar, unir, conhecer, ler e compreender. E que tais habilidades são desenvolvidas a partir do trabalho com a Teoria dos Campos Conceituais, promovendo a diferenciação dos tipos de situação-problema e a utilização de novas estratégias de resolução pelos alunos.

\section{Referências}

Alsina Pastells, À. I. Desenvolvimento de competências Matemáticas com recursos lúdicomanipulativos para crianças de 6 a 12 anos: metodologia. Curitiba: Base Editorial. 2009. 
Antunes, A. Trabalhando habilidades: construindo ideias. São Paulo: Scipione. 2001.

Dante, L. R. Didática da resolução de problemas de Matemática: $1^{\mathrm{a}}$ a $5^{\mathrm{a}}$ séries. $\left(12^{\mathrm{a}}\right.$. ed.). São Paulo: Ática. 2007.

Etcheverria, T. C. Um estudo sobre o campo conceitual aditivo nos anos iniciais do Ensino Fundamental. Caxambu: UFRB. 2010.

Freitas, M. T. A. Vigotski e Bakhtin - psicologia e educação: um intertexto. São Paulo: Ática.1994.

Magina, S., Campos, T. M. M., Nunes, T., Citirana, V. Repensando adição, subtração: contribuições da teoria dos campos conceituais (3a ed.). São Paulo: Proem. 2001.

Moreira, M. A. A teoria dos campos conceituais de Vergnaud, o ensino de ciências e a pesquisa nesta área. Investigações em Ensino de Ciências, v. 7, n. 1, 7-29. Acesso em 05 de março de 2014. Disponível em: http://www.if.ufrgs.br/ienci/artigos/Artigo_ID80/v7_n1_a2002.pdf. 2002

Perrenoud, P. Construir competências desde a escola. Porto Alegre: Artmed. 1999.

Piaget, J. Epistemologia genética (3ª . ed.). São Paulo: Martins Fontes. 2007.

Vergnaud, G. Teoria dos campos conceituais. In: J. Brun (Org.). Didática das Matemáticas (pp 155-191). Lisboa: Instituto Piaget. 1993.

Vergnaud, G. A teoria dos campos conceituais na construção dos conhecimentos. Revista Geema: Tempo de Romper para Fecundar, v. (4), 9-19. 1996.

Vergnaud, G. A criança, a matemática e a realidade. Curitiba: UFPR, 2014.

Vygotsky, L. S. A formação social da mente: o desenvolvimento dos processos psicológicos superiores. São Paulo: Martins Fontes. 1984.

Zabala, A.; Arnau, L. Como aprender e ensinar competências. Porto Alegre: Artmed Editora. 2010. 


\section{APÊNDICE A - Situações-problema utilizadas no pré-teste e no pós-teste}

a) Mariana foi ao supermercado com seu pai. Eles compraram 8 iogurtes de morango e 7 de salada de frutas. Quantos iogurtes eles compraram?

b) Fernanda ganhou de aniversário 3 bonecas. Ela já tinha 13 bonecas. Com quantas bonecas Fernanda ficou?

c) Juliana tinha alguns lápis de cor. Ela ganhou outros lápis de cor novos. Observe os desenhos:

Lápis de cor que ela tinha

Lápis de cor que ela ganhou
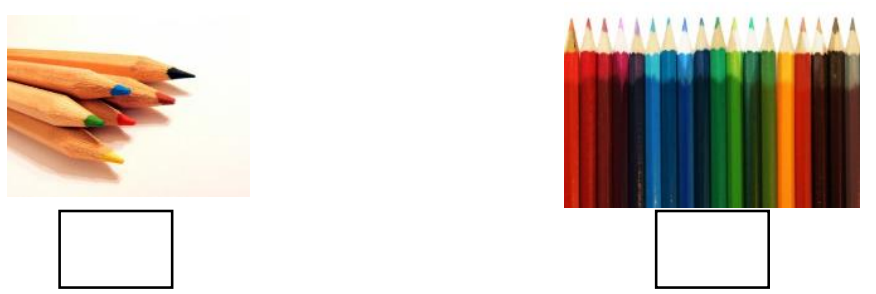

Com quantos lápis ela ficou?

d) Carlos tinha pirulitos e deu alguns para sua irmã Sofia. Observe o desenho dos pirulitos que Carlos tinha e dos que deu para Sofia:

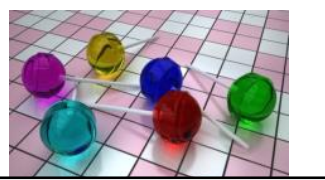

Pirulitos que Carlos tinha

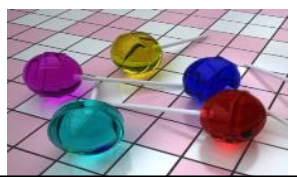

Pirulitos que Carlos tem agora

Quantos pirulitos Carlos deu para sua irmã Sofia?

e) João tem 7 revistas com histórias da Mônica e 9 com histórias do Cascão. Quantas revistas com histórias da Mônica e do Cascão João tem?

f) Pedro ganhou uma caixa com 14 bombons. Ele comeu alguns e ficou com 8 bombons. Quantos bombons Pedro comeu?

g) No final do jogo de gude, Pedro ficou com 14 gudes. Pedro perdeu 6 gudes no jogo. Quantas gudes Pedro tinha antes de iniciar o jogo?

h) Em uma turma há 24 alunos. 13 são meninas. Quantos são os meninos?

i) João ganhou de sua avó um saco com 12 biscoitos. Alguns eram de maisena e outros de polvilho. Sete biscoitos eram de maisena. Quantos biscoitos eram de polvilho?

j) Maria tinha alguns biscoitos e ganhou 3 biscoitos de sua avó, ficando com 14 biscoitos. Quantos biscoitos Maria tinha antes?

Submetido em janeiro de 2017

Aprovado em maio de 2017 